\title{
An Empirical Analysis of Poverty Reduction Factors in National-Level Poverty-Stricken Counties Taking Sichuan Province as an Example
}

\author{
Li Lei ${ }^{1}$ Chenxi Liu ${ }^{1}$ Zhenyi $\mathrm{Ji}^{1, *}{ }^{1}$ Zhixin Shu ${ }^{1}$
}

${ }^{1}$ Sichuan Agricultural University, Chengdu, Sichuan, China
${ }^{*}$ Corresponding author. Email: $155052781 @ q q . c o m$

\begin{abstract}
Poverty has always been the development priority in China. Sichuan, a key target of national poverty alleviation and reduction, is vital for the overall poverty alleviation across China. Based on the data of poverty-stricken counties in Sichuan from 2013 to 2017, this paper employs multiple linear regression model to analyze the factors affecting residents' saving deposit balance. Results show that the proportion of working population in the secondary industry and the tertiary industry, per capita oil production, the proportion of fixed-line telephone significantly sway the saving deposit of residents. Relevant policy suggestions are also proposed based on the results.
\end{abstract}

Keywords: national-level poverty-stricken counties, rural poverty, factors, multiple linear regression model

\section{INTRODUCTION}

Since the reform and opening up, China's poverty alleviation and development has been transformed from extensive model into targeted poverty alleviation, which benefits a swath of poverty-stricken household. At the 18th National Congress of the Communist Party of China (CPC), China repeatedly stressed the importance of poverty reduction in rural povertystricken areas in building moderately prosperous society in all respects.

On the verge of realizing the great goal of a moderately prosperous society in all respects, China is about to embark on a tough period of poverty alleviation. Sichuan, with its huge poor population, has been the headache in the national battle against poverty. Between the end of 2013 and the end of 2019, the number of poverty-stricken counties in Sichuan has slashed from 88 to 7 , and the number of povertystricken villages has been reduced from more than 10,000 to 300 . The number of people still living in poverty has dropped by $96 \%$ from 6 million. Numerically, a huge victory in the battle against poverty has been achieved. But Sichuan alone accounted for 15.5 percent among counties in China that fail to realize poverty reduction. So far, there are still 204,000 people trapped in poverty in Sichuan, and the poor in seven poverty-stricken counties accounted for 97.6 percent. It can be seen that despite the considerable achievements in poverty alleviation over the past decades, Sichuan still faces challenges. Some areas in Sichuan are still mired in poverty, and those that have just been lifted out of poverty are also facing the challenge of consolidating their gains and preventing poverty-returning.

In recent years, the way the country helps the poor has changed. In order to further improve poverty alleviation, the original poverty alleviation evaluation in Sichuan should be reviewed and summarized. Further in-depth research should also be carried out. Most previous studies focus on the indicator system and evaluation methods. Research on such core factors influencing poverty reduction performance as employment, industrial structure, communication facilities, fiscal expenditure and financial loans is rare. Sichuan province has also ridden the train of economic development thanks to more than ten years of reform and poverty alleviation. However, the challenges imposed on poverty-stricken areas are still severe, and the causes of poverty varies in poverty-stricken counties, which requires further study and analysis.

The academic circle has explored the effects of various poverty alleviation policies from different perspectives. After investigation, Zhang Xian found that since poverty alleviation, the development of economy and society has reached a new level, and industrial restructure has been actively carried out (Zhang Xian, 2000). Since the implementation of Great Western Development Strategy and targeted poverty alleviation, a large number of poor people in the west have been lifted out of poverty and have been able to pursue higher levels of needs, such as education and personal quality, in a more perfect social welfare and infrastructure. The three prefectures in southern 
Xinjiang have repeatedly excelled in poverty alleviation in previous years, but their performance in ecological environment, and production and living wellbeing tell a different story. (Wang Baozhen, Gong Xinshu, 2013) The Wumeng mountain area of Yunnan has achieved satisfactory result in poverty alleviation through agricultural industrialization, but there is still a long journey ahead before the completion of a moderately well-off society in an all-round way. The region is still plagued by issues including high proportion of primary industry, agricultural products without unique features and poor self-development ability of people. The situation in contiguous destitute areas of Tibet has gradually improved thanks to targeted poverty alleviation. The social development has been enhanced, but the ecological environment still needs to be further strengthened (Zhang Chao, Wang Jiawei, Wan Guangcai, 2018).

Existing studies reveal the gap in poverty alleviation among different regions in China, which leads to stage bottlenecks. In a word, the implementation of government policies, the efficiency of subordinates' implementation, public participation and administrative environment greatly influence poverty alleviation. (Jin Yongzhu, Ding Zhaopan, 2017) As for rural areas, agricultural industrial structure, infrastructure such as roads and education (Shuai Jing et al., 2017), especially land reclamation with significant poverty reduction effect (Zhang Qi, Shi Chao, 2018) can greatly increase income. In terms of targeted poverty alleviation, the concept of poverty alleviation, family income structure, accurate identification and industrial development, as well as social capital possessed by poverty-stricken households significantly sway the performance of targeted poverty alleviation.

From the perspective of targeted poverty alleviation, this paper makes an in-depth exploration of the factors influencing the performance of targeted poverty alleviation in poverty-stricken counties in Sichuan and their effects. Key points and factors influencing poverty alleviation are cleared based on statistical data of 66 state-level poverty-stricken counties in Sichuan from 2013 to 2017 from the prospective of employment, industrial structure, communication facilities, fiscal expenditure, financial loans and so on, thus helping the government develop a targeted, precision and effective poverty alleviation framework. Such move lays a more targeted theoretical foundation for further implementation of targeted poverty alleviation. In this critical period of poverty reduction, rational allocation of poverty alleviation resources and scientific analysis of factors affecting poverty alleviation performance serve as main driving force for improving performance and conducting in-depth research on the thinking and methods of targeted poverty alleviation.

\section{STATUS QUO OF POVERTY-STRICKEN COUNTIES IN SICHUAN PROVINCE}

State-level poverty-stricken counties, the focus of national poverty alleviation work, are all over the country's 16 provincial-level administrative regions, led by Tibet autonomous region, followed by Guizhou, Guangxi Zhuang Autonomous Region, Inner Mongolia Autonomous Region, Sichuan, Shaanxi and Yunnan. At present, there are a total of 183 counties and districts in Sichuan. Excluding 20 districts and counties in Chengdu, there are 163 counties and districts, accounting for $54 \%$ of the total.

"Fig. 1" shows the average poverty rate of 66 statelevel poverty-stricken counties in Sichuan from 2010 to 2017. The average poverty rate in 2010 was 31.45 percent, or more than a third, and fell by 4.33 percentage points, or 13.77 percent, to 27.12 percent in 2011. In 2012, the average poverty rate was $19.66 \%$, a decrease of 7.46 percentage points or $27.5 \%$ compared with 2011, a significantly larger decrease. From 2013 to 2015 , the incidence of poverty was $18.57 \%, 18.73 \%$ and $15.13 \%$, respectively, a total decline of 4.34 percentage points and a gradual decline. The poverty rate was 11.56 percent in 2016, a drop of 3.57 percentage points or $23.6 \%$ from 2015. In 2016, the average poverty incidence in 66 state-level poor counties was $7.43 \%$, a decrease of 4.13 percentage points, or $35.72 \%$, reaching the maximum decline from 2010 to 2017. 


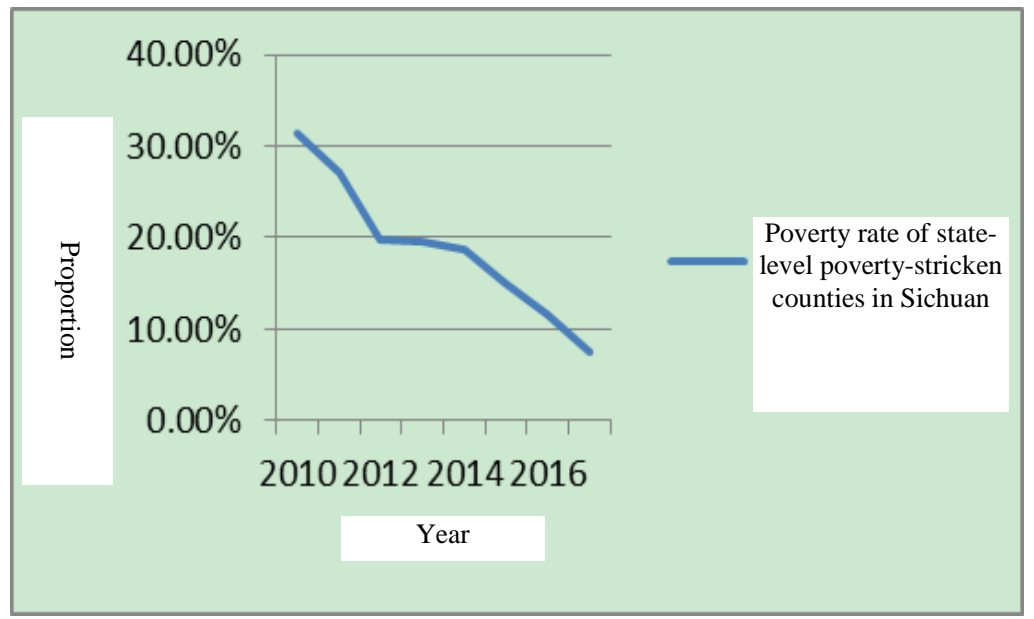

Fig. 1. The average poverty rate of 66 state-level poverty-stricken counties in Sichuan from 2010 to 2017.

On the whole, poverty alleviation in Sichuan province achieved great leap forward results from 2010 to 2017 , with poverty rate dropping by 24.02 percentage points. However, there are still 36 nationallevel poverty-stricken counties such as Yanyuan County, Yuexi County and Ganluo County, which are widely distributed in Guangyuan city, Ganzi Prefecture, Nanchong City, Bazhong City, Aba Prefecture, Liangshan Prefecture and other regions in Sichuan Province. Therefore, it is necessary to further analyze and summarize the specific influencing factors of poverty alleviation performance based on previous experience, so as to achieve overall poverty alleviation in Sichuan province.

\section{MODEL AND VARIABLE}

\section{A. Model selection}

Various indicators of 145 counties in Sichuan province are pooled and 36 state-level poverty-stricken counties are further selected. Given that poverty results from all factors, multiple linear regression model was employed to analyze factors causing poverty in the rural areas of 36 national-level poverty-stricken counties.

The specific regression model is as follows:

$$
\mathrm{Y}=\beta_{0}+\beta_{1} \mathrm{X}_{1}+\beta_{2} \mathrm{X}_{2}+\beta_{3} \mathrm{X}_{3}+\ldots \beta_{\mathrm{n}} \mathrm{X}_{\mathrm{n}}+\varepsilon
$$

Where $\mathrm{Y}$ represents explained variable, savings surplus, $X_{1}, X_{2} \ldots X_{n}$ the explanatory variable of working population in the tertiary industry and secondary industry, oil output, number of fixed-line telephone, public financial expenditure and other factors, $\beta_{0}$ a constant term, $\beta_{1}-\beta_{\mathrm{n}}$ a coefficient, and $\varepsilon$ an error term.

\section{B. Variable selection}

There are many factors affecting rural poverty. The relevant indicators identified at present include the proportion of working population in the primary, secondary and tertiary industries, public financial expenditure, public financial expenditure, added value of agriculture and animal husbandry, various taxes, welfare adoption units, and various loan amounts of financial institutions at the end of the year. Based on the principles of systematicness, comparability and scientificity of the index selection, as well as the availability, completeness and consistency of the data caliber, combined with the existing research results, the six indicators covering the proportion of working population in the secondary industry and the tertiary industry, per capita oil production, the proportion of fixed-line telephone, public financial expenditure, and loan balance of financial institutions at the end of the year are employed as independent variable, while household savings balance as dependent variable Y.

The integrated development of primary, secondary and tertiary industries and poverty alleviation by developing industries have prevailed since the 13th Five-Year Plan. The focus of poverty alleviation by developing industries lies in giving people fishing rods, not fish, so as to allow the poor in less-developing areas to rid poverty by themselves and avoid povertyreturning. The proportion of agricultural population is essential for economic and social development. Generally speaking, the higher the proportion, the higher the poverty rate. The proportion of the working population in the secondary industry reveals the industrialization and whether the county is in the stage of industrial transformation. The development of the secondary industry promotes that of the primary industry, and industrialization and mechanization free up labor market, thus enabling more people to benefit from and engage in the secondary industry. Since it is 
directly proportional to people's income, the working population in the secondary industry is vital to reduce the incidence of poverty. The working population of the tertiary industry mirrors industrial transformation in poor areas. Increasing the proportion of tertiary industry in poor areas and realizing the integrated development of primary industry, secondary industry and tertiary industry are targets of poverty alleviation. The loans of financial institutions at the end of the year could be channeled to purchase agricultural machinery, promote the large-scale development of agricultural mechanization in poor counties, improve industrial infrastructure, and develop tertiary industries such as tourism. More relevant loans helps enhance agricultural production, farmers' income and transformation to the secondary and tertiary industries, thus reducing the incidence of poverty to a certain extent. The number of fixed-line phones indicates rural communication facilities, the bridge of information and communication, which improves people's livelihood and promote local economy, thus reducing the incidence of poverty. Oil output is an indispensable component in agricultural production. The higher the oil yield is, the more significant its role on reducing the incidence of poverty is. Public financial expenditure, an essential driver of rural production, matters significantly in improving rural infrastructure, providing funds for enterprise renovation, science, education, culture and health, etc. Generally speaking, the higher the public financial expenditure is, the more conducive it is to the development and construction of poor areas.

\section{Empirical and regression results}

1) Model estimation results: Statistical software was adopted to perform multiple linear regression. First, the validity of the results was tested, and the Pvalues were all less than 0.5 . Then, the dependent variables and independent variables are analyzed by regression analysis. The specific variables are explained and the results are estimated by multiple linear regression model.

$\mathrm{Y}=0.0428+0.1458 \mathrm{X}_{1}+6.5916 \mathrm{X}_{2}+3.6800 \mathrm{X}_{3}+6.5534$ $\mathrm{X}_{4}+0.0752 \mathrm{X}_{5}+0.2215 \mathrm{X}_{6}+\varepsilon$

Where $\mathrm{Y}$ serves as explained variable savings surplus, $X_{1}$ the working population of the tertiary industry, $\mathrm{X}_{2}$ the working population of the secondary industry, $\mathrm{X}_{3}$ oil production, $\mathrm{X}_{4}$ the number of fixed-line telephones, $\mathrm{X}_{5}$ public finance expenditure and $\mathrm{X}_{6}$ the loan amount of financial institutions at the end of the year.

2) Interpretation of result: The regression analysis results show that the coefficient value of fixed-line telephone is as high as $6.5 \%$, indicating the construction of communication facilities in poor areas was in a critical period of poverty alleviation. Complete communication facilities helps to reduce the poverty rate in the poor areas. The coefficient of the working population of the secondary industry is positive, greater than $5 \%$, and the coefficient of the working population of the secondary industry is 6 times that of the tertiary industry, indicating that the more working population in the secondary and tertiary industry, the more income of the residents in poor areas, and the efficiency of the secondary industry is significantly higher than that of the tertiary industry. The coefficient of per capita oil output, $3 \%$, is between the coefficient of employees in the secondary and tertiary industries. This can not be ignored, indicating that the primary industry excels in the poor areas still dominated by it, and the development of the oil industry can effectively promote farmers' income. The public financial expenditure and the loan coefficient of financial institutions are less than $1 \%$, indicating its positive but limited effect on poverty reduction in poor areas. Relevant government policies should focus on improving production and living conditions in poor areas, providing basic public services and relief to poor people and severely impoverished groups bereaved of working ability. However, attention should be paid to whether it will lead to people's dependency psychology, thus reducing the effect of poverty reduction. The low loan coefficient of financial institutions at the end of the year can be explained by the poor implementation of of poverty alleviation policies. The investigation shows that some financial institutions in Sichuan overemphasize risk control and measure the borrowing standards of poor households based on internal system of conventional risk prevention, which may result in low efficiency of capital turnover or the situation that loans are unavailable to eligible poor households.

The specific data are shown in the "Table I" below: 
TABLE I. REGRESSION ANALYSIS RESULT

\begin{tabular}{|c|c|c|c|c|c|c|c|c|}
\hline & Coefficients & $\begin{array}{l}\text { Standard } \\
\text { error }\end{array}$ & t Stat & P-value & $\begin{array}{c}\text { Lower } 9 \\
5 \%\end{array}$ & $\begin{array}{c}\text { Upper } 9 \\
5 \%\end{array}$ & $\begin{array}{l}\text { Lower } \\
95 \%\end{array}$ & $\begin{array}{l}\text { Upper } \\
95 \%\end{array}$ \\
\hline Intercept & 0.042826 & 0.075603 & 30.566464 & 0.571259 & -0.10561 & 0.19126 & -0.10561 & 0.19126 \\
\hline $\begin{array}{l}\text { Norking population in } \\
\text { the tertiary industry }\end{array}$ & 1.145756 & 0.387979 & 90.375681 & 0.707268 & -0.61598 & 0.907493 & -0.61598 & 0.907493 \\
\hline $\begin{array}{l}\text { Working population in } \\
\text { the secondary industry }\end{array}$ & 6.091683 & 0.349541 & 118.85811 & 1.67E-64 & 5.905414 & 7.277952 & 5.9054147 & 7.277952 \\
\hline Oil-bearing output & 3.680063 & 0.809013 & 34.548832 & $6.35 \mathrm{E}-06$ & 52.091692 & & 2.091 & 5.268433 \\
\hline Fixed-line telephone & 6.553423 & 0.41295 & 515.86979 & $1.06 \mathrm{E}-48$ & 5.742661 & 7.364186 & 5.742661 & 7.364186 \\
\hline $\begin{array}{l}\text { Public financial } \\
\text { expenditure }\end{array}$ & 0.07522 & 0.034256 & 62.195842 & 0.028429 & 0.007964 & 0.142476 & 0.007964 & 0.142476 \\
\hline $\begin{array}{l}\text { Loan coefficient of } \\
\text { financial institutions at } \\
\text { the end of the year }\end{array}$ & 0.221588 & 0.017631 & 12.56795 & $8 \mathrm{E}-33$ & 0.186972 & 0.256204 & 0.186972 & 0.256204 \\
\hline
\end{tabular}

\section{CONCLUSION}

The regression results reveal that the proportion of working population in the secondary and tertiary industry, per capita oil output, the proportion of fixedline telephone matter a lot to per capita savings balance of residents. The following suggestions are proposed based on regression results.

The government should strongly support the secondary industry by encouraging local people to find jobs nearby and engage in the manufacturing Industrial parks and industrial concentration district provide opportunity for economy development in counties. The management of industrial parks should be further optimized for assembling. The opportunity of open economy should be grasped, leading industries be cultivated, and implementation of brand strategy be heeded to enhance the popularity of enterprises, accelerate the scientific and automation. In addition, attention should be paid to increasing the jobs of enterprises and promoting local residents to find jobs nearby. Meanwhile, preferential policies of tax and financial credit should be endowed to the manufacturing industry.

Based on local ecological environment and featured products, investment on tourism service facilities and basic transportation facilities should be mounted, and the Internet and various media could be employed to promote featured industries and products, so as to better the development of the tertiary industries including service and tourism. It is feasible to highlight advantages based on local characteristics, cultivate and develop competitive industries, upgrade traditional service industry, promote the scale and level of the tertiary industry, and increase farmers' income.

Oil-bearing crops are not only convenient for planting but also highly profitable compared with other crops, which contributes much to farmers' income increase and economic development. The villagers should be advised to improve the quality of oil while planting oil crops, cultivate high-quality varieties, develop professional breeding gardens, which helps the standardization of cultivation technology, the bettering of processing and transformation, the popularization of practical technology, the acceleration of oil production mechanization, and the industrialization of production and management. Support for oil-bearing industry should be strengthened, and subsidies for such crops should be actively implemented.

The proportion of fixed-line telephone reveals the development of communication industry, which, due to its characteristics, serves as not only a basic industry closely related to people's daily life, but also a special service industry favorably supporting social economy, culture, politics and people's life. Therefore, the external environment of communication industry should be further optimized, professionals and technical talents should be pooled to solve technical problems encountered and promote the construction of communication infrastructure. What's more, the fixedline telephone charges of residents should be appropriately subsidized to increase its penetration. 


\section{References}

[1] Zhu Qianyu. Analysis on the Efficiency of Poverty Relief Funds from China's Central Government [J]. Science \& Technology Progress and Policy, 2003,20(16):36-38. (in Chinese)

[2] Zhang Xian. An Analysis of the Achievements of the Poverty Region Support Policy in the Nationalities Areas [J]. Journal of Southwest University for Nationalities (Philosophy and Social Sciences), 2000(03): 18-24+126. (in Chinese)

[3] Yan Guosheng. Discussion on the performance of poverty alleviation in Building a Well-off Society in Shaanxi Province [J]. Commercial Research, 2007(08): 171-172. (in Chinese)

[4] Xiang Yanping. Investigation and Study on Perception of Performance Evaluation of Helping the Poor by Tourism of Xiang, E, Yu and Qian Border Region - Taking Dehang Village as an Example [J]. Resource Development \& Market, 2009,25(07): 655-657. (in Chinese)

[5] Xu Xiaoyong, Lai Jingsheng, Cun Jiaju. Patterns and Achievements of Rural Poverty Reduction and Policy Suggestions in Western Areas of China [J]. Research of Agricultural Modernization, 2010,31(02): 161-165. (in Chinese)

[6] Wang Baozhen, Gong Xinshu. Performance evaluation of poverty alleviation and development in ethnic minority border areas - In case of the impoverished areas of the three connected districts in South Xinjiang [J]. Guangdong Agricultural Sciences, 2013,40(24): 214-218. (in Chinese)

[7] Xun Guanyu. Performance Analysis of Poverty Alleviation Through Agricultural Industrialization in Wumengshan Area in Yunnan Province [J]. Journal of China Agricultural Resources and Regional Planning, 2017,38(01): 193-198. (in Chinese)

[8] Zhang Chao, Wang Jiawei, Wan Guangcai. On Comprehensive Performance Evaluation of Targeted Poverty Alleviation of Contiguous Destitute Areas in Tibet [J]. Journal of Tibet University, 2018,33(04): 126-131. (in Chinese)

[9] Jin Yongzhu, Ding Zhaopan. Factors Affecting a Project Scheme's Poverty Reduction Performance - An Investigation and Analysis of Poverty Alleviation in Wuling Mountain, the Wumeng Shan and the Yunnan Guangxi Guizhou Rocky Area [J]. Public Administration Review, 2017,10(03): 46-70+214. (in Chinese)

[10] Shuai Jing, Cheng Jinhua, Shuai Chuanmin, Li Wenjing, Guo Qing, Cheng Xin, Ding Liping. Evaluation on accurate poverty eradication effects of IFAD Projects in rural China: based on household net income $[\mathrm{J}]$. China Polulation.Resources and Environment, 2017,27(02): 126 -134. (in Chinese)

[11] Zhang Qi, Shi Chao. Study on Performance of Land Consolidation in Poverty Alleviation [J]. Journal of Northwest Sci-Tech University of Agriculture and Forestry (Social Science), 2018,18(06): 90-96. (in Chinese)

[12] Nie Jun, Shu Xihong. Evaluation and Influencing Factors of Precision Poverty Alleviation in E'ri Village of Qinghai Tibetan Region [J]. Journal of The Beifang University Of Nationalities, 2019(01): 31-39. (in Chinese)

[13] Liu Hubei, Min Weiqi, Chen Liang. Research on the relationship between social capital and poverty alleviation performance of "first secretary" [J]. Jiangxi Social Sciences, 2019,39(09): 212-218. (in Chinese)

[14] Zhang Zhijuan. Performance Evaluation of Rural Tourism Accurate Poverty Alleviation in Henan Province - A Case Study of Gushi County in Dabie Mountain [J]. Journal of China Agricultural Resources and Regional Planning, 2018,39(10): 184-190. (in Chinese)

[15] Du Xingyang, Yang Qicheng, Shao Honglu. A Research on the Performance of Financial Targeted Poverty Alleviation - An Empirical Analysis Based on Rural Poverty lleviation in 9 Cities in Hunan Province [J]. Journal of Agrotechnical Economics, 2019(04): 84-94. (in Chinese)
[16] Wei Yan, Xu Yun, Gao Yingxia. Study on Performance Evaluation of Health Poverty Alleviation in Poverty-stricken Areas - Based on the Survey in Five Provinces [J]. The World of Survey and Research, 2020(04): 24-30. (in Chinese)

[17] Chen Chuanbo, Wang Liaomu, Liu Yongqiang, Yue Yu, Zhang Ying. Performance Analysis of the Implementation of Targeted Poverty Alleviation Through Science and Technology in Tibetan Areas of Sichuan [J]. Soft Science, 2020,34(05): 139144. (in Chinese) 